\title{
Sleep disturbance is associated with not only shorter sleep duration, but also longer time in bed: a Japanese general population survey
}

\author{
Masahiro Suzuki ${ }^{1} \cdot$ Ryuji Furihata ${ }^{1} \cdot$ Chisato Konno $^{1} \cdot$ Michiko Konno $^{2} \cdot$ Yoshitaka Kaneita $^{3} \cdot$ Takashi Ohida $^{3}$. \\ Yasuhiro Gon ${ }^{4} \cdot$ Makoto Uchiyama ${ }^{1}$
}

Received: 9 April 2019 / Accepted: 18 June 2019 / Published online: 21 June 2019

(c) The Author(s) 2019

\begin{abstract}
Individuals with chronic insomnia tend to increase their amount of time in bed (TIB) to secure more opportunity for sleep, which in turn, may aggravate and perpetuate the condition. It remains unclear whether this behavioral feature of clinical insomniacs, which are targets of cognitive-behavioral therapy for insomnia, can be generalized to individuals with sleep disturbance in the general population. To investigate the relation between TIB and sleep disturbance in the general adult population, we conducted a cross-sectional survey with face-to-face interviews in August and September 2009. Data from 2559 randomly-sampled adults living in Japan were analyzed. Participants were asked about difficulty initiating sleep (DIS), difficulty maintaining sleep (DMS), early morning awakening (EMA), sleep duration, and TIB. Any sleep difficulties (ASDs) were defined as having DIS, DMS, and/or EMA. The associations between sleep difficulties (DIS, DMS, EMA, and ASDs) and hourly-stratified sleep duration and TIB were examined using logistic regression analyses. DIS, DMS, EMA, and ASDs were found to be associated with a sleep duration $<6 \mathrm{~h}$. Furthermore, DIS, DMS, and ASDs were associated with a TIB $\geq 9 \mathrm{~h}$. Sufferers of DIS, DMS, EMA, or ASDs had shorter sleep duration and longer wakefulness in bed compared with nonsufferers. To our best knowledge, this is the first epidemiological study reporting an association between prolonged TIB and sleep disturbance in the general population. Our findings suggest that optimizing TIB may be an important tactic to improve sleep disturbance in the general population.
\end{abstract}

Keywords Epidemiology $\cdot$ Insomnia $\cdot$ Sleep disturbance $\cdot$ Sleep hygiene $\cdot$ Sleep restriction therapy $\cdot$ Time in bed

\section{Introduction}

Insomnia is defined as repeated sleep disturbance that occurs despite adequate time and opportunity for sleep and results in various types of daytime distress or impairment [1].

Masahiro Suzuki

suzuki.masahiro94@nihon-u.ac.jp

1 Department of Psychiatry, Nihon University School of Medicine, 30-1 Oyaguchi-Kamicho, Itabashi-ku, Tokyo 173-8610, Japan

2 Center of University-wide Education, Saitama Prefectural University, 820 Sannomiya, Koshigaya, Saitama 343-8540, Japan

3 Division of Public Health, Department of Social Medicine, Nihon University School of Medicine, 30-1 Oyaguchi-Kamicho, Itabashi-ku, Tokyo 173-8610, Japan

4 Division of Respiratory Medicine, Department of Internal Medicine, Nihon University School of Medicine, 30-1 Oyaguchi-Kamicho, Itabashi-ku, Tokyo 173-8610, Japan
Sleep disturbance such as difficulty initiating sleep (DIS), difficulty maintaining sleep (DMS), or early morning awakening (EMA) reportedly increases the risk for subsequent psychiatric and physical disorders, including depression [2], hypertension [3], cardiovascular disease [4], and diabetes mellitus [5]. Therefore, proper interventions to improve sleep are expected to play an important role in public health promotion. However, no effective public health interventions for preventing and treating sleep disturbance have been established.

It is commonly known that individuals with chronic insomnia tend to increase their amount of time in bed (TIB) to secure more opportunity for sleep [6, 7]. However, this behavior can, in turn, lead to increased wakefulness, fragmented sleep, and variability in its timing $[8,9]$. Based on these observations, sleep restriction therapy (SRT), which aims to consolidate sleep and increase the sleep drive by manipulating TIB according to systematic rules, was developed [10]. SRT is routinely applied as a core element of 
contemporary cognitive-behavioral therapy for insomnia (CBTi) [11-13] together with stimulus control therapy but is also used as a single-component intervention [14]. Miller et al. [14] recently reviewed the efficacy of SRT as a standalone intervention for insomnia disorder, and concluded that single-component SRT is an effective treatment with moderate-to-large effect sizes for sleep diary measures of sleep onset latency, wake time after sleep onset, and sleep efficiency, as well as a small effect size for increased total sleep time. These effect sizes are comparable to those of hypnotic pharmacotherapy [15], suggesting that SRT is a powerful stand-alone intervention for insomnia.

Given the recent evidence on the efficacy of SRT in clinical insomniacs, optimizing TIB may be an effective strategy to improve sleep disturbance in the general population. However, no epidemiological facts indicating the association between prolonged TIB and sleep disturbance have been provided. In other words, it remains unclear whether these behavioral features of clinical insomnia, which have been described as the theoretical background of CBTi, can be generalized to individuals with sleep disturbance in the general population.

If this association is found in the general population, educational interventions based on the theory of SRT may improve public health regarding not only sleep health but also psychiatric and physical health. Therefore, we conducted an epidemiological study to investigate the associations of sleep disturbance with TIB and sleep duration in a large sample from the Japanese general adult population, with a particular interest in clarifying the association between TIB and sleep disturbance after adjusting for the confounding effects of sociodemographic variables.

\section{Methods}

\section{Selection of participants}

This study was a part of the Nihon University Sleep and Mental Health Epidemiology Project (NUSMEP) [16-19], a survey aimed at determining the factors associated with depression and sleep problems in the general Japanese population. The NUSMEP was conducted as a part of an omnibus survey in August and September 2009 through a commission to a polling agency (Central Research Services, Japan). In the survey, a three-stage stratified sampling method was used to select the study population. Municipalities were stratified into 31 units representing 12 geographical blocks and three city scales (metropolitan area, other city, town and village) in proportion to the population distribution in 2008. In the first stage, the target municipalities were randomly selected from each unit. In the second stage, a total of 8000 homes were randomly selected from a digital house map of the selected municipalities. In the third stage, the interviewer visited the homes, finding that residents were present in 4738 of them. An individual aged $\geq 20$ years was randomly selected from each home. Finally, 2559 individuals gave oral informed consent and participated in the survey (response rate $54.0 \%$ ), which involved completing a face-toface interview with a trained interviewer using a panel-listed structured questionnaire. Participants were reimbursed with a 500-yen book coupon for their participation in this survey. For the present report, we obtained electronic data files for each participant's relevant interview component, with no personal identifiers.

\section{Data collection}

A structured questionnaire was developed that asked about sociodemographic characteristics, health attitudes, health behavior, lifestyle, and sleep. We used three questions on sleep difficulties that allowed us to infer sleep disturbance in the subjects, with reference to the Japanese version of the Pittsburgh Sleep Quality Index [20, 21], together with questions about sleep habits.

The following questions about sleep experienced during the previous month were included in the questionnaire:

How often have you had difficulty falling asleep? (DIS)

How often have you woken up frequently at night? (DMS)

How often have you woken up too early in the morning? (EMA)

Each question had four possible replies: "not at all," "less than once a week," "once or twice a week," or "three or more times a week." "Once or twice a week" and "three or more times a week" were taken as affirmative answers, in accordance with our previous study [17]. The presence of DIS, DMS, or EMA was defined when affirmative answers to the question were obtained. Any sleep difficulties (ASDs) were defined as having DIS, DMS, and/or EMA.

The following questions that asked habitual bed and rise times as well as total sleep duration during the previous month were embedded in the questionnaire:

What time have you usually gone to bed at night? (bedtime)

What time have you usually gotten up in the morning? (rise time)

How many hours and minutes of actual sleep did you get at night? (sleep duration)

TIB was defined as the time from bedtime to rise time. Wakefulness duration in bed was calculated by subtracting sleep duration from TIB. Sleep duration and TIB were 
stratified hourly into five levels (“< $<6$ h", “6-7 h", “7-8 h", "8-9 h" and " $\geq 9 \mathrm{~h}$ ") for non-parametric analyses.

Perceived physical and mental health status during the previous month were asked and answered by selecting one response from the following: very sufficient/sufficient/nor$\mathrm{mal} /$ insufficient/very insufficient. For both questions, "very insufficient" and "insufficient" were considered to indicate poor health status, and the remainder were considered to indicate good health status.

The following question was used to identify the presence of psychological stress: "Did you feel dissatisfied or distressed, or have difficulties and stress in the previous month?" (much/some/little/none). Those who answered "much" were defined as being stressed, while those who answered "some/little/none" were defined as being unstressed.

The sociodemographic variables analyzed in the present study included gender, age (20-29, 30-39, 40-49, 50-59, 60-69 and $\geq 70$ years), educational achievement (junior high school, senior high school, and college or higher), marital status (married and unmarried), subjective economic status (upper, upper-middle, lower- middle, and lower), and community size (a city with a population of $\geq 150,000$ was defined as a big city and a city with the population of $<150,000$ was defined as a town or village).

\section{Statistical analyses}

Gender and age differences for the prevalence ratio of hourly-stratified data were examined using the Chi squared test. Analysis of variance or the $t$ test was used when comparing continuous variables. The association between sleep duration and TIB was assessed using Pearson's correlation analysis.

Multiple logistic regression analyses were utilized to examine the associations between sleep difficulties (DIS, DMS, EMA, or ASDs) and hourly-stratified sleep duration and TIB (five levels each). A series of crude logistic regression analyses were conducted to examine the association between sleep difficulties (DIS, DMS, EMA or ASDs) and hourly-stratified sleep duration and TIB. After the crude analyses, first, we carried out multiple logistic regression analyses to adjust for the confounding effects of gender and age. Second, we performed multiple logistic regression analyses to adjust for the confounding effects of the sociodemographic variables (gender, age, educational achievement, marital status, economic status, and city scale), physical and psychological health statuses, and psychological stress. Odds ratios (ORs) and 95\% confidence intervals (95\% CI) were calculated for the series of logistic regression analyses.

To evaluate the attributable risk of the difference between TIB and sleep duration for sleep difficulties, a dichotomized variable for wakefulness duration in bed was also created. Wakefulness duration in bed of $\geq 0.5 \mathrm{~h}$ was defined as long. The associations between long wakefulness duration in bed and sleep difficulties (DIS, DMS, EMA or ASDs) were examined using multiple logistic regression analyses.

Statistical significance was set at 0.05 . All analyses were performed using SPSS version 24 (IBM Corporation, Armonk, NY, USA).

\section{Results}

\section{Study participants}

Of the 2559 participants, 17 were excluded because of missing or impossible data on the variables in the analysis (TIB or marital status). Therefore, the final sample used in the analyses comprised of 2542 participants. Table 1 shows the sex and age distribution of the study participants, together with Japan Census data from 2008 [22]. In both samples, the distribution patterns seemed comparable with respect to sex and age distribution.

\section{Sleep duration and TIB}

Table 2 shows the mean sleep duration and TIB, as well as the hourly-stratified prevalence, sorted by age groups and gender. The mean sleep duration of the overall sample
Table 1 Percentage of study participants and the general population classified according to sex and age

\begin{tabular}{lcclll}
\hline Age group (years) & \multicolumn{2}{l}{ Present study } & & \multicolumn{2}{l}{ Census (2008) } \\
\cline { 2 - 3 } & Male (\%) & Female (\%) & & Male (\%) & Female (\%) \\
\hline $20-29$ & 14.1 & 10.9 & & 15.0 & 13.3 \\
$30-39$ & 18.6 & 16.8 & & 18.7 & 17.0 \\
$40-49$ & 17.6 & 15.7 & & 16.2 & 14.9 \\
$50-59$ & 16.1 & 18.0 & & 17.4 & 16.4 \\
$60-69$ & 17.7 & 19.0 & & 16.3 & 16.2 \\
$\geq 70$ & 15.9 & 19.6 & & 16.3 & 22.2 \\
Total & 100.0 & 100.0 & & 100.0 & 100.0 \\
$N$ & 1151 & 1391 & & 50,295 (thousands) & 54,064 (thousands) \\
\hline
\end{tabular}


Table 2 Sleep duration and time in bed by gender and age

\begin{tabular}{|c|c|c|c|c|c|c|c|c|c|c|c|c|c|}
\hline \multirow[t]{2}{*}{ Age (years) } & \multirow[t]{2}{*}{$N$} & \multirow{2}{*}{$\begin{array}{l}\text { Sleep duration }(\mathrm{h})^{\mathrm{a}} \\
\text { Mean }(\mathrm{SD})\end{array}$} & \multicolumn{5}{|c|}{ Sleep duration $(\%)^{\mathrm{b}}$} & \multirow{2}{*}{$\begin{array}{l}\text { TIB }(h)^{\mathrm{c}} \\
\text { Mean }(\mathrm{SD})\end{array}$} & \multicolumn{5}{|c|}{$\operatorname{TIB}(\%)^{\mathrm{d}}$} \\
\hline & & & $<6 \mathrm{~h}$ & $6 \mathrm{~h}-$ & $7 \mathrm{~h}-$ & $8 \mathrm{~h}-$ & $\geq 9 \mathrm{~h}$ & & $<6 \mathrm{~h}$ & $6 \mathrm{~h}-$ & $7 \mathrm{~h}-$ & $8 \mathrm{~h}-$ & $\geq 9 \mathrm{~h}$ \\
\hline \multicolumn{14}{|l|}{ Male } \\
\hline $20-29$ & 162 & $6.6(1.1)$ & 12.3 & 37.7 & 34.6 & 11.7 & 3.7 & $6.9(1.3)$ & 8.0 & 22.8 & 37.0 & 19.8 & 12.3 \\
\hline $30-39$ & 214 & $6.5(1.0)$ & 15.4 & 36.0 & 38.3 & 8.9 & 1.4 & $6.8(1.1)$ & 10.7 & 17.8 & 43.0 & 24.8 & 3.7 \\
\hline $40-49$ & 203 & $6.5(1.1)$ & 19.7 & 32.0 & 33.0 & 13.8 & 1.5 & $6.9(1.1)$ & 7.9 & 23.6 & 34.5 & 24.1 & 9.9 \\
\hline $50-59$ & 185 & $6.6(1.1)$ & 17.3 & 32.4 & 33.0 & 14.6 & 2.7 & $6.9(1.1)$ & 7.6 & 20.5 & 41.6 & 19.5 & 10.8 \\
\hline $60-69$ & 204 & $7.0(1.2)$ & 11.8 & 24.5 & 31.9 & 27.9 & 3.9 & $7.5(1.1)$ & 3.4 & 11.3 & 28.9 & 36.8 & 19.6 \\
\hline$\geq 70$ & 183 & $7.4(1.3)$ & 9.3 & 16.4 & 24.6 & 36.6 & 13.1 & $8.0(1.3)$ & 3.3 & 6.0 & 17.5 & 37.7 & 35.5 \\
\hline Total & 1151 & $6.8(1.2)$ & 14.4 & 29.8 & 32.7 & 18.9 & 4.3 & $7.1(1.2)$ & 6.9 & 16.9 & 33.9 & 27.3 & 15.0 \\
\hline \multicolumn{14}{|l|}{ Female } \\
\hline $20-29$ & 152 & $6.7(1.2)$ & 19.7 & 25.7 & 32.9 & 19.7 & 2.0 & $7.1(1.1)$ & 7.2 & 20.4 & 30.3 & 29.6 & 12.5 \\
\hline $30-39$ & 234 & $6.5(1.1)$ & 19.7 & 34.6 & 29.1 & 15.8 & 0.9 & $6.9(1.1)$ & 8.5 & 24.4 & 30.8 & 28.6 & 7.7 \\
\hline $40-49$ & 218 & $6.2(1.0)$ & 28.4 & 39.9 & 23.9 & 7.3 & 0.5 & $6.4(1.1)$ & 12.8 & 38.5 & 32.1 & 14.2 & 2.3 \\
\hline $50-59$ & 250 & $6.2(1.1)$ & 29.6 & 31.6 & 31.2 & 7.6 & 0.0 & $6.6(1.1)$ & 13.6 & 23.6 & 39.6 & 19.6 & 3.6 \\
\hline $60-69$ & 264 & $6.6(1.1)$ & 17.8 & 34.5 & 31.1 & 15.2 & 1.5 & $7.0(1.1)$ & 7.2 & 14.0 & 40.9 & 28.0 & 9.8 \\
\hline$\geq 70$ & 273 & $7.0(1.3)$ & 13.2 & 25.3 & 28.2 & 24.9 & 8.4 & $7.7(1.2)$ & 2.9 & 7.7 & 25.6 & 40.7 & 23.1 \\
\hline Total & 1391 & $6.5(1.2)$ & 21.2 & 32.1 & 29.3 & 15.1 & 2.4 & $7.0(1.2)$ & 8.6 & 20.8 & 33.4 & 27.1 & 10.1 \\
\hline \multicolumn{14}{|l|}{ Combined } \\
\hline $20-29$ & 314 & $6.6(1.1)$ & 15.9 & 31.8 & 33.8 & 15.6 & 2.9 & $7.0(1.2)$ & 7.6 & 21.7 & 33.8 & 24.5 & 12.4 \\
\hline $30-39$ & 448 & $6.5(1.1)$ & 17.6 & 35.3 & 33.5 & 12.5 & 1.1 & $6.8(1.1)$ & 9.6 & 21.2 & 36.6 & 26.8 & 5.8 \\
\hline $40-49$ & 421 & $6.4(1.1)$ & 24.2 & 36.1 & 28.3 & 10.5 & 1.0 & $6.6(1.1)$ & 10.5 & 31.4 & 33.3 & 19.0 & 5.9 \\
\hline $50-59$ & 435 & $6.4(1.1)$ & 24.4 & 32.0 & 32.0 & 10.6 & 1.1 & $6.7(1.1)$ & 11.0 & 22.3 & 40.5 & 19.5 & 6.7 \\
\hline $60-69$ & 468 & $6.7(1.2)$ & 15.2 & 30.1 & 31.4 & 20.7 & 2.6 & $7.2(1.2)$ & 5.6 & 12.8 & 35.7 & 31.8 & 14.1 \\
\hline$\geq 70$ & 456 & $7.2(1.3)$ & 11.6 & 21.7 & 26.8 & 29.6 & 10.3 & $7.8(1.2)$ & 3.1 & 7.0 & 22.4 & 39.5 & 28.1 \\
\hline Total & 2542 & $6.6(1.2)$ & 18.1 & 31.0 & 30.8 & 16.8 & 3.2 & $7.0(1.2)$ & 7.8 & 19.0 & 33.6 & 27.2 & 12.3 \\
\hline
\end{tabular}

$S D$ standard deviation, $T I B$ time in bed

${ }^{\mathrm{a}}$ Gender effect $p<0.001$, age effect $p<0.001$, gender $\times$ age effect $p=0.008$ (two-way ANOVA)

${ }^{\mathrm{b}}$ Gender effect $p=0.013$, age effect $p<0.001$ (Chi squared test)

${ }^{\mathrm{c}}$ Gender effect $p<0.001$, age effect $p<0.001$, gender $\times$ age effect $p<0.001$ (two-way ANOVA)

${ }^{\mathrm{d}}$ Gender effect $p<0.001$, age effect $p<0.001$ (Chi squared test)

was $6.6 \pm 1.2 \mathrm{~h}$. Sleep duration was $0.3 \mathrm{~h}$ longer in men than in women $(t=5.0, p<0.0001)$, and was prolonged with advanced age $(F=29.0 ; d f=5,2536 ; p<0.0001)$. The distribution of hourly-stratified sleep duration significantly differed between men and women $\left(\chi^{2}=31.6, d f=4\right.$, $p<0.0001)$, as well as among age groups $\left(\chi^{2}=221.0\right.$, $d f=20, p<0.0001)$.

In the overall sample, the mean TIB was $7.0 \pm 1.2 \mathrm{~h}$, which was $0.4 \mathrm{~h}$ longer than the mean sleep duration $(t=23.5, p<0.0001)$. TIB was $0.2 \mathrm{~h}$ longer in men than in women $(t=4.1, p<0.0001)$ and was prolonged with advanced age $(F=61.3 ; d f=5,2536 ; p<0.0001)$. The distribution of hourly-stratified TIB significantly differed between men and women $\left(\chi^{2}=20.0, d f=4, p<0.0001\right)$, as well as among age groups $\left(\chi^{2}=318.2, d f=20, p<0.0001\right)$. TIB was strongly correlated with sleep duration $(\mathrm{r}=0.74$, $p<0.0001)$.

\section{Sleep disturbance}

Table 3 shows the prevalence of the four types of sleep difficulties by gender and age. The prevalences of DIS $\left(\chi^{2}=5.8\right.$, $d f=1, p=0.016)$, DMS $\left(\chi^{2}=8.0, d f=1, p=0.005\right)$, and ASDs $\left(\chi^{2}=4.8, d f=1, p=0.028\right)$ were significantly higher in women than in men. No significant gender difference was found for EMA. The prevalences of DIS $\left(\chi^{2}=17.0, d f=5, p=0.004\right)$, DMS $\left(\chi^{2}=78.0, d f=5, p<0.0001\right)$, EMA $\left(\chi^{2}=47.2, d f=5\right.$, $p<0.0001)$, and ASDs $\left(\chi^{2}=72.4, d f=5, p<0.0001\right)$ differed significantly among the age groups, being higher with advanced age. 
Table 3 Prevalence of sleep difficulties by gender and age

\begin{tabular}{llllc}
\hline & ASDs $(\%)^{\mathrm{a}}$ & DIS $(\%)^{\mathrm{b}}$ & DMS $(\%)^{\mathrm{c}}$ & ${\text { EMA }(\%)^{\mathrm{d}}}^{\mathrm{n}}$ \\
Male & & & & \\
$20-29$ & 17.9 & 13.0 & 11.7 & 4.9 \\
$30-39$ & 22.0 & 11.7 & 15.0 & 9.3 \\
$40-49$ & 23.6 & 12.8 & 16.7 & 9.4 \\
$50-59$ & 34.6 & 11.4 & 29.2 & 15.1 \\
$60-69$ & 36.8 & 13.7 & 29.4 & 12.7 \\
$\geq 70$ & 47.5 & 14.8 & 40.4 & 17.5 \\
Total & 30.4 & 12.9 & 23.7 & 11.6 \\
Female & & & & \\
$20-29$ & 29.6 & 17.1 & 20.4 & 7.2 \\
$30-39$ & 31.6 & 12.0 & 25.2 & 5.6 \\
$40-49$ & 26.1 & 14.2 & 22.9 & 6.9 \\
$50-59$ & 34.0 & 13.2 & 30.0 & 12.4 \\
$60-69$ & 35.6 & 15.9 & 30.3 & 14.8 \\
$\geq 70$ & 45.8 & 24.2 & 38.1 & 19.0 \\
Total & 34.5 & 16.2 & 28.7 & 11.6 \\
Combined & & & & \\
$20-29$ & 23.6 & 15.0 & 15.9 & 6.1 \\
$30-39$ & 27.0 & 11.8 & 20.3 & 7.4 \\
$40-49$ & 24.9 & 13.5 & 20.0 & 8.1 \\
$50-59$ & 34.3 & 12.4 & 29.7 & 13.6 \\
$60-69$ & 36.1 & 15.0 & 29.9 & 13.9 \\
$\geq 70$ & 46.5 & 20.4 & 39.0 & 18.4 \\
Total & 32.7 & 14.7 & 26.4 & 11.6 \\
\hline
\end{tabular}

$A S D s$ any sleep difficulties, DIS difficulty initiating sleep, DMS difficulty maintaining sleep, EMA early morning awakening

${ }^{\mathrm{a}}$ Gender effect $p=0.028$, age effect $p<0.001$ (Chi squared test)

${ }^{\mathrm{b}}$ Gender effect $p=0.016$, age effect $p=0.004$ (Chi squared test)

${ }^{\mathrm{c}}$ Gender effect $p<0.001$, age effect $p<0.001$ (Chi squared test)

${ }^{\mathrm{d}}$ Gender effect $p=0.988$, age effect $p<0.001$ (Chi squared test)

\section{Associations between sleep duration and sleep disturbance}

Table 4 shows the results of the logistic regression analyses, which were conducted to investigate the associations between sleep duration and four types of sleep difficulties. Multiple logistic regression analyses revealed that insomnia symptoms were significantly associated with sleep duration $<6 \mathrm{~h}$ (DIS, DMS, EMA, and ASDs) and 6-7 h (EMA) after adjusting for the confounding effects of the sociodemographic variables, and physical and psychological conditions.

\section{Associations between TIB and sleep disturbance}

Table 5 shows the results of the logistic regression analyses, which were conducted to investigate the associations between TIB and the four types of sleep difficulties. Multiple logistic regression analyses revealed that DIS, DMS, and ASDs were significantly associated with a TIB $\geq 9 \mathrm{~h}$ after adjusting for the confounding effects of the sociodemographic, physical, and psychological variables. TIB did not show a statistically significant association with EMA after adjusting for the confounding effects of the sociodemographic, physical, and psychological variables.

\section{Associations between TIB and sleep disturbance in the subpopulation whose sleep duration was $<7 \mathrm{~h}$}

We also investigated associations between TIB and sleep disturbance in a subpopulation consisting of subjects with a sleep duration $<7 \mathrm{~h}(n=1250)$. The results of the multiple logistic regression analyses showed that a TIB of $\geq 8 \mathrm{~h}$ or $\geq$ $9 \mathrm{~h}$ was significantly associated with DIS ( $7 \mathrm{~h}$ : OR $1.0 ; 8 \mathrm{~h}$ : OR $2.0 ; \geq 9$ h: OR 3.7 ), DMS (7 h: OR $1.0 ; 8$ h: OR $2.4 ; \geq$ 9 h: OR 4.0), EMA ( 7 h: OR 1.0; 8 h: OR 2.9; $\geq 9$ h: OR 2.6), and ASDs ( $7 \mathrm{~h}:$ OR $1.0 ; 8 \mathrm{~h}:$ OR $2.2 ; \geq 9$ h: OR 4.9 ). A dose-response was observed with respect to DIS, DMS, and ASDs.

\section{Sleep duration, wakefulness duration in bed, and TIB with respect to the morbidity of sleep difficulties}

Table 6 shows the sleep duration, wakefulness duration in bed, and TIB with respect to the morbidity of sleep difficulties. Subjects with ASDs experienced approximately 30 min longer wakefulness duration than those without (0.7 vs. 0.2 h). Subjects with DIS, DMS, or EMA slept 0.2-0.5 fewer $\mathrm{h}$ than those without. TIB was $0.2 \mathrm{~h}$ longer in subjects with than in subjects without DMS (7.2 vs. $7.0 \mathrm{~h}$ ).

\section{Association between a long wakefulness duration in bed and sleep difficulties}

In the overall sample, 939 participants (36.9\%) had a long wakefulness duration in bed $(\geq 0.5 \mathrm{~h})$. A long wakefulness duration in bed showed 2.0-2.5 times stronger associations with sleep difficulties, in comparison with a wakefulness duration in the bed of $<0.5 \mathrm{~h}$ (Table 7).

\section{Discussion}

In this study, we demonstrated that sleep disturbance was associated with not only shorter sleep duration, but also longer TIB. To the best of our knowledge, this is the first epidemiological evidence of an association between prolonged TIB and sleep disturbance. The present results suggest that the behavioral features of clinical insomnia, which have been described as the theoretical background of CBTi, 
Table 4 Association between sleep duration and sleep difficulties

\begin{tabular}{|c|c|c|c|c|}
\hline & $\begin{array}{l}\text { Prevalence of symp- } \\
\text { tom }(\%)\end{array}$ & $\begin{array}{l}\text { Crude } \\
\text { OR }(95 \% \mathrm{CI})\end{array}$ & $\begin{array}{l}\text { Adjusted }^{\mathrm{a}} \\
\text { OR }(95 \% \mathrm{CI})\end{array}$ & $\begin{array}{l}\text { Adjusted }^{\mathrm{b}} \\
\text { OR }(95 \% \text { CI })\end{array}$ \\
\hline \multicolumn{5}{|c|}{ ASDs (h) } \\
\hline$<6$ & 47.3 & $2.4(1.9-3.1)^{* * *}$ & $2.6(2.0-3.3)^{* * *}$ & $2.2(1.7-2.8)^{* * *}$ \\
\hline 6 & 29.8 & $1.1(0.9-1.4)$ & $1.2(0.9-1.5)$ & $1.2(0.9-1.5)$ \\
\hline 7 & 27.2 & 1.0 & 1.0 & 1.0 \\
\hline 8 & 31.1 & $1.2(0.9-1.6)$ & $1.0(0.8-1.3)$ & $1.0(0.8-1.3)$ \\
\hline$\geq 9$ & 37.8 & $1.6(1.0-2.6)^{*}$ & $1.1(0.7-1.9)$ & $1.0(0.6-1.7)$ \\
\hline \multicolumn{5}{|c|}{ DIS (h) } \\
\hline$<6$ & 27.3 & $3.0(2.2-4.1)^{* * *}$ & $3.2(2.3-4.3)^{* * *}$ & $2.6(1.9-3.6)^{* * *}$ \\
\hline 6 & 13.4 & $1.2(0.9-1.7)$ & $1.3(0.9-1.7)$ & $1.2(0.9-1.7)$ \\
\hline 7 & 14.7 & 1.0 & 1.0 & 1.0 \\
\hline 8 & 10.3 & $0.9(0.6-1.3)$ & $0.8(0.5-1.2)$ & $0.7(0.5-1.1)$ \\
\hline$\geq 9$ & 13.4 & $1.2(0.6-2.4)$ & $0.9(0.5-1.8)$ & $0.8(0.4-1.6)$ \\
\hline \multicolumn{5}{|c|}{ DMS (h) } \\
\hline$<6$ & 36.9 & $1.9(1.5-2.5)^{* * *}$ & $2.0(1.6-2.6)^{* * *}$ & $1.7(1.3-2.3)^{* * *}$ \\
\hline 6 & 23.6 & $1.0(0.8-1.3)$ & $1.0(0.8-1.3)$ & $1.0(0.8-1.3)$ \\
\hline 7 & 23.1 & 1.0 & 1.0 & 1.0 \\
\hline 8 & 25.8 & $1.2(0.9-1.5)$ & $1.0(0.7-1.3)$ & $1.0(0.7-1.3)$ \\
\hline$\geq 9$ & 30.5 & $1.5(0.9-2.4)$ & $1.1(0.6-1.8)$ & $0.9(0.5-1.6)$ \\
\hline \multicolumn{5}{|c|}{ EMA (h) } \\
\hline$<6$ & 22.3 & $3.5(2.5-5.0)^{* * *}$ & $4.0(2.8-5.7)^{* * *}$ & $3.2(2.2-4.6)^{* * *}$ \\
\hline 6 & 11.2 & $1.5(1.1-2.2)^{*}$ & $1.7(1.2-2.4)^{* *}$ & $1.6(1.1-2.3)^{* *}$ \\
\hline 7 & 11.6 & 1.0 & 1.0 & 1.0 \\
\hline 8 & 8.0 & $1.1(0.7-1.6)$ & $0.8(0.5-1.3)$ & $0.8(0.5-1.2)$ \\
\hline$\geq 9$ & 12.2 & $1.7(0.9-3.5)$ & $1.1(0.5-2.3)$ & $1.0(0.5-2.1)$ \\
\hline
\end{tabular}

$O R$ odds ratio, $C I$ confidence interval, $A S D s$ any sleep difficulties, $D I S$ difficulty initiating sleep, $D M S$ difficulty maintaining sleep, $E M A$ early morning awakening

$* p<0.05, * * p<0.01, * * * p<0.001$

${ }^{a}$ Adjusted for gender and age

${ }^{\mathrm{b}}$ Adjusted for gender, age, educational achievement, marital status, economic status, city scale, physical and psychological health statuses, and psychological stress can be generalized to individuals with sleep disturbance in the general population.

In the present study, we randomly selected study participants throughout Japan using a three-stage stratified sampling method. The sex and age distributions were comparable to those from the census conducted around the same time; therefore, our participants can be considered as being representative of the general adult population in Japan [22].

Previous epidemiological studies in the Japanese general adult population have reported that the most frequent sleep duration was $6 \mathrm{~h}$, followed by $7 \mathrm{~h}[23,24]$; we confirmed this finding in our sample. The present study found that sleep duration was longer in men than in women, and was prolonged with advanced age. These results were also consistent with those from previous epidemiological studies conducted in Japan [23, 24].

The mean TIB of the overall present sample was $7.0 \mathrm{~h}$, which was $0.4 \mathrm{~h}$ longer than the mean sleep duration. There are a few studies reporting both sleep duration and TIB based on a laboratory setting or a particular age group. Natale et al. studied sleep parameters obtained from actigraphy in 126 insomnia patients and 282 normal sleepers in a laboratory setting and found that sleep duration and TIB in the normal sleepers aged 7-65 years were $7.6 \mathrm{~h}$ and $8.1 \mathrm{~h}$, respectively [25]. Van den Berg et al. investigated the sleep parameters of over 5000 elderly persons aged 58-100 y and reported that the mean sleep duration and TIB were 6.9 and $7.7 \mathrm{~h}$, respectively [26]. Although there are some methodological differences between our study and theirs, the results seem comparable.

The changes of TIB according to sex and age seemed to be in parallel with those of sleep duration. The present result that TIB was increased with advanced age was not consistent with the data obtained from the meta-analysis of quantitative sleep electroencephalogram variables in healthy subjects aged 5-102 years [27]. In the meta-analysis conducted 
Table 5 Association between time in bed and sleep difficulties

\begin{tabular}{|c|c|c|c|c|}
\hline & $\begin{array}{l}\text { Prevalence of symp- } \\
\text { tom }(\%)\end{array}$ & $\begin{array}{l}\text { Crude } \\
\text { OR }(95 \% \mathrm{CI})\end{array}$ & $\begin{array}{l}\text { Adjusted }^{\mathrm{a}} \\
\text { OR }(95 \% \text { CI })\end{array}$ & $\begin{array}{l}\text { Adjusted }^{\mathrm{b}} \\
\text { OR }(95 \% \mathrm{CI})\end{array}$ \\
\hline \multicolumn{5}{|c|}{ ASDs (h) } \\
\hline$<6$ & 34.7 & $1.2(0.9-1.6)$ & $1.2(0.9-1.7)$ & $1.0(0.7-1.4)$ \\
\hline 6 & 28.3 & $0.9(0.7-1.1)$ & $0.9(0.7-1.2)$ & $0.9(0.7-1.2)$ \\
\hline 7 & 31.0 & 1.0 & 1.0 & 1.0 \\
\hline 8 & 29.8 & $0.9(0.8-1.2)$ & $0.9(0.7-1.1)$ & $0.8(0.7-1.1)$ \\
\hline$\geq 9$ & 48.9 & $2.1(1.6-2.8)^{* * *}$ & $1.8(1.4-2.4)^{* * *}$ & $1.7(1.3-2.3)^{* * *}$ \\
\hline \multicolumn{5}{|c|}{ DIS (h) } \\
\hline$<6$ & 19.6 & $1.6(1.1-2.3)^{*}$ & $1.6(1.1-2.4)^{*}$ & $1.2(0.8-1.9)$ \\
\hline 6 & 13.2 & $1.0(0.7-1.4)$ & $1.0(0.7-1.4)$ & $1.0(0.7-1.4)$ \\
\hline 7 & 14.7 & 1.0 & 1.0 & 1.0 \\
\hline 8 & 12.7 & $0.9(0.7-1.3)$ & $0.9(0.6-1.2)$ & $0.9(0.6-1.2)$ \\
\hline$\geq 9$ & 21.7 & $1.8(1.3-2.5)^{* *}$ & $1.6(1.2-2.2)^{*}$ & $1.5(1.0-2.1)^{*}$ \\
\hline \multicolumn{5}{|c|}{ DMS (h) } \\
\hline$<6$ & 25.1 & $1.0(0.7-1.4)$ & $1.0(0.7-1.5)$ & $0.8(0.6-1.2)$ \\
\hline 6 & 21.9 & $0.8(0.6-1.1)$ & $0.9(0.7-1.2)$ & $0.9(0.7-1.1)$ \\
\hline 7 & 25.3 & 1.0 & 1.0 & 1.0 \\
\hline 8 & 24.9 & $1.0(0.8-1.2)$ & $0.9(0.7-1.1)$ & $0.9(0.7-1.1)$ \\
\hline$\geq 9$ & 40.9 & $2.0(1.6-2.7)^{* * *}$ & $1.8(1.3-2.4)^{* * *}$ & $1.7(1.3-2.3)^{* * *}$ \\
\hline \multicolumn{5}{|c|}{ EMA (h) } \\
\hline$<6$ & 15.1 & $1.6(1.0-2.5)^{*}$ & $1.8(1.1-2.8)^{*}$ & $1.4(0.8-2.2)$ \\
\hline 6 & 11.4 & $1.2(0.8-1.7)$ & $1.3(0.9-1.9)$ & $1.3(0.9-1.9)$ \\
\hline 7 & 9.9 & 1.0 & 1.0 & 1.0 \\
\hline 8 & 10.4 & $1.1(0.8-1.5)$ & $0.9(0.7-1.3)$ & $0.9(0.6-1.3)$ \\
\hline$\geq 9$ & 16.6 & $1.8(1.2-2.6)^{* *}$ & $1.4(1.0-2.1)$ & $1.3(0.9-2.0)$ \\
\hline
\end{tabular}

$O R$ odds ratio, $C I$ confidence interval, $A S D s$ any sleep difficulties, $D I S$ difficulty initiating sleep, $D M S$ difficulty maintaining sleep, $E M A$ early morning awakening

$* p<0.05, * * p<0.01, * * * p<0.001$

${ }^{\mathrm{a}}$ Adjusted for gender and age

${ }^{\mathrm{b}}$ Adjusted for gender, age, educational achievement, marital status, economic status, city scale, physical and psychological health statuses, and psychological stress by Ohayon et al., TIB decreased from young to middle age and remained unchanged between middle to elderly. The difference in the changes associated with aging between our results and those of the meta-analysis may be attributable to the differences in the selected populations: a considerable percentage of the aged populations in the present study would have inevitably had aging-related physical or mental diseases, whereas the meta-analysis involved only healthy subjects.

The present study found that the prevalence of sleep difficulties increased with advanced age, and was significantly higher in women than in men. These results are in agreement with those from most previous epidemiological studies on insomnia [28].

We found that sleep difficulties were associated with sleep duration $<6 \mathrm{~h}$ (DIS, DMS, EMA, and ASDs) and 6-7 h (EMA). By contrast, TIB $>9$ h was associated with DIS, DMS, and ASDs. The present results suggest that the behavioral features of clinical insomniacs can be generalized to the general population with sleep disturbance and that public health problems regarding sleep problems may be improved by interventions based on the theory of SRT. Given the present result that $32.7 \%$ of the participants had ASDs, highlighting the behavioral features of insomnia and the importance of optimizing TIB may have a dramatic effect on public health in Japan.

We found that the subjects with sleep disturbance experienced wakefulness for about $50 \mathrm{~min}$ in bed, compared with about 20 min for those without. Considering that the TIB of subjects with sleep difficulties was $0.1-0.2 \mathrm{~h}$ longer, optimizing TIB might have reduced wakefulness in bed, which is likely to be one of the most frustrating times for subjects with subjective sleep disturbance, by about one-third to one-fourth.

The present study had some limitations. First, as it was cross-sectional in design, causal relationships could not be 
Table 6 Sleep duration, wakefulness duration in bed, and TIB with respect to the morbidity of sleep difficulties

\begin{tabular}{|c|c|c|c|c|}
\hline \multirow[t]{2}{*}{ Symptoms } & \multirow[t]{2}{*}{$N$} & Sleep duration (h) & $\begin{array}{l}\text { Wakefulness } \\
\text { duration in bed } \\
\text { (h) }\end{array}$ & TIB (h) \\
\hline & & Mean (SD) & Mean (SD) & Mean (SD) \\
\hline \multicolumn{5}{|l|}{$\operatorname{ASDs}^{\mathrm{a}, \mathrm{b}, \mathrm{c}}$} \\
\hline Yes & 830 & $6.5(1.3)$ & $0.7(1.1)$ & $7.2(1.4)$ \\
\hline No & 1712 & $6.7(1.3)$ & $0.2(0.6)$ & $7.0(1.1)$ \\
\hline \multicolumn{5}{|l|}{$D_{I S}{ }^{a, b}$} \\
\hline Yes & 374 & $6.2(1.3)$ & $0.9(1.2)$ & $7.1(1.4)$ \\
\hline No & 2168 & $6.7(1.1)$ & $0.3(0.8)$ & $7.0(1.2)$ \\
\hline \multicolumn{5}{|l|}{$\mathrm{DMS}^{\mathrm{a}, \mathrm{b}, \mathrm{c}}$} \\
\hline Yes & 672 & $6.5(1.3)$ & $0.7(1.2)$ & $7.2(1.3)$ \\
\hline No & 1870 & $6.7(1.1)$ & $0.3(0.7)$ & $7.0(1.2)$ \\
\hline \multicolumn{5}{|l|}{$\mathrm{EMA}^{\mathrm{a}, \mathrm{b}}$} \\
\hline Yes & 294 & $6.1(1.4)$ & $0.9(1.2)$ & $7.1(1.4)$ \\
\hline No & 2242 & $6.7(1.1)$ & $0.3(0.8)$ & $7.0(1.2)$ \\
\hline
\end{tabular}

$T I B$ time in bed, $S D$ standard deviation, $A S D$ s any sleep difficulties, $D I S$ difficulty initiating sleep, $D M S$ difficulty maintaining sleep, $E M A$ early morning awakening

${ }^{\text {a }}$ Significant difference for sleep duration $(t$ test, $p<0.05)$

${ }^{\mathrm{b}}$ Significant difference for wakefulness duration $(t$ test, $p<0.05)$

${ }^{\mathrm{c}}$ Significant difference for TIB $(t$ test, $p<0.05$ )

Table 7 Association between wakefulness duration in bed $\geq 0.5 \mathrm{~h}$ and sleep difficulties

\begin{tabular}{llll}
\hline Symptoms & $\begin{array}{l}\text { Crude } \\
\text { OR }(95 \% \mathrm{CI})\end{array}$ & $\begin{array}{l}\text { Adjusted }^{\mathrm{a}} \\
\text { OR }(95 \% \mathrm{CI})\end{array}$ & $\begin{array}{l}\text { Adjusted }^{\mathrm{b}} \\
\text { OR }(95 \% \mathrm{CI})\end{array}$ \\
\hline ASDs & $2.4(2.0-2.8)^{* * *}$ & $2.3(1.9-2.7)^{* * * *}$ & $2.2(1.9-2.7)^{* * *}$ \\
DIS & $2.6(2.1-3.3)^{* * *}$ & $2.6(2.0-3.2)^{* * *}$ & $2.5(1.9-3.1)^{* * *}$ \\
DMS & $2.1(1.8-2.6)^{* * *}$ & $2.1(1.7-2.5)^{* * *}$ & $2.0(1.7-2.5)^{* * *}$ \\
EMA & $2.6(2.0-3.3)^{* * *}$ & $2.4(1.9-3.1)^{* * *}$ & $2.3(1.8-3.0)^{* * *}$ \\
\hline
\end{tabular}

$O R$ odds ratio, $C I$ confidence interval, $A S D$ s any sleep difficulties, $D I S$ difficulty initiating sleep, $D M S$ difficulty maintaining sleep, $E M A$ early morning awakening

$* p<0.05, * * p<0.01, * * * p<0.001$

${ }^{a}$ Adjusted for gender and age

${ }^{\mathrm{b}}$ Adjusted for gender, age, educational achievement, marital status, economic status, city scale, physical and psychological health statuses, and psychological stress

determined, even for items in which an association was indicated. A future prospective study will be required to clarify the causality of the relationships observed in the present study. Second, sleep disturbance and sleep-related variables were assessed using a retrospective, self-report approach. Although some studies have reported that self-report data on sleep status concur with physiologic data [29, 30], objective data (i.e., physiologic measurements such as electroencephalography) are desirable. Third, a nonresponse bias due to the sampling method should be considered. The response ratio obtained in the present study (54\%) should be considered carefully in the light of a nonresponse bias, although the distributions of gender and age did not differ between population-estimated data and the present study sample. Finally, factors that could specifically influence the associations of sleep disturbance with sleep duration and TIB in the present study were not completely excluded using multiple logistic regression analyses. However, the questions on sleep duration, TIB, and sleep disturbance were not likely to be related to religious beliefs, ethical attitudes, or specific values, which could have substantially distorted the associations.

In conclusion, the present study demonstrated that sleep disturbance was associated with not only shorter sleep duration but also longer TIB in the general adult population in Japan. Our findings suggest that optimizing TIB may be an important tactic to improve sleep disturbance in the general population.

Acknowledgements The authors acknowledge the study participants for their contributions in making this study possible.

Funding This study was supported in part by a Research Grant from the Japan Society for the Promotion of Science and Technology Agency (22591301, 25861032, and 26507012), a Research Grant on the Development of New Medical Devices from the Japan Agency for Medical Research and Development (JP18hk0102041), and an Intramural Research Grant (29-1) for Neurological and Psychiatric Disorders from the National Center of Neurology and Psychiatry.

\section{Compliance with ethical standards}

Conflict of interest The authors declare that there are no conflict of interests regarding the publication of this paper.

Ethical approval This study was approved by the ethics committee of the Nihon University School of Medicine.

Open Access This article is distributed under the terms of the Creative Commons Attribution 4.0 International License (http://creativecommons.org/licenses/by/4.0/), which permits unrestricted use, distribution, and reproduction in any medium, provided you give appropriate credit to the original author(s) and the source, provide a link to the Creative Commons license, and indicate if changes were made.

\section{References}

1. AmericanAcademy of Sleep Medicine. International classification of sleep disorders. 3rd ed. Darien: American Academy of Sleep Medicine; 2014.

2. Yokoyama E, Kaneita Y, Saito Y, Uchiyama M, Matsuzaki Y, Tamaki T, et al. Association between depression and insomnia subtypes: a longitudinal study on the elderly in Japan. Sleep. 2010;33:1693-702.

3. Meng L, Zheng Y, Hui R. The relationship of sleep duration and insomnia to risk of hypertension incidence: a meta-analysis of prospective cohort studies. Hypertens Res. 2013;36:985-95. 
4. Meisinger C, Heier M, Lowel H, Schneider A, Doring A. Sleep duration and sleep complaints and risk of myocardial infarction in middle-aged men and women from the general population: the MONICA/KORA Augsburg cohort study. Sleep. 2007;30:1121-7.

5. Cappuccio FP, D’Elia L, Strazzullo P, Miller MA. Quantity and quality of sleep and incidence of type 2 diabetes: a systematic review and meta-analysis. Diabetes Care. 2010;33:414-20.

6. Miles LE, Dement WC. Sleep and aging. Sleep. 1980;3:1-220.

7. Natale V, Leger D, Martoni M, Bayon V, Erbacci A. The role of actigraphy in the assessment of primary insomnia: a retrospective study. Sleep Med. 2014;15:111-5.

8. Reynold AM, Bowles ER, Saxena A, Fayad R, Youngstedt SD. Negative effects of time in bed extension: a pilot study. J Sleep Med Disord. 2014;1:1002.

9. Arnal PJ, Sauvet F, Leger D, van Beers P, Bayon V, Bougard C, et al. Benefits of sleep extension on sustained attention and sleep pressure before and during total sleep deprivation and recovery. Sleep. 2015;38:1935-43.

10. Spielman AJ, Saskin P, Thorpy MJ. Treatment of chronic insomnia by restriction of time in bed. Sleep. 1987;10:45-56.

11. Schwartz DR, Carney CE. Mediators of cognitive-behavioral therapy for insomnia: a review of randomized controlled trials and secondary analysis studies. Clin Psychol Rev. 2012;32:664-75.

12. Edinger JD, Marsh GR, Holescher TJ, Lipper S, Ionescupioggia M. A cognitive behavioral-therapy for sleep-maintenance insomnia in older adults. Psychol Aging. 1992;7:282-9.

13. Riemann D, Baglioni C, Bassetti C, Bjorvatn B, Groselj LD, Ellis $\mathrm{JG}$, et al. European guideline for the diagnosis and treatment of insomnia. J Sleep Res. 2017;26:675-700.

14. Miller CB, Espie CA, Epstein DR, Friedman L, Morin CM, Pigeon WR, et al. The evidence base of sleep restriction therapy for treating insomnia disorder. Sleep Med Rev. 2014;18:415-24.

15. Riemann D, Perlis ML. The treatments of chronic insomnia: a review of benzodiazepine receptor agonists and psychological and behavioral therapies. Sleep Med Rev. 2009;13:205-14.

16. Suzuki M, Furihata R, Konno C, Kaneita Y, Ohida T, Uchiyama M. Stressful events and coping strategies associated with symptoms of depression: a Japanese general population survey. J Affect Disord. 2018;238:482-8.

17. Furihata R, Uchiyama M, Takahashi S, Suzuki M, Konno C, Osaki $\mathrm{K}$, et al. The association between sleep problems and perceived health status: a Japanese nationwide general population survey. Sleep Med. 2012;13:831-7.

18. Furihata R, Uchiyama M, Suzuki M, Konno C, Konno M, Takahashi $\mathrm{S}$, et al. Association of short sleep duration and short time in bed with depression: a Japanese general population survey. Sleep Biol Rhythm. 2015;13:136-45.
19. Furihata R, Konno C, Suzuki M, Takahashi S, Kaneita Y, Ohida $\mathrm{T}$, et al. Unhealthy lifestyle factors and depressive symptoms: a Japanese general adult population survey. J Affect Disord. 2018;234:156-61.

20. Doi Y, Minowa M, Uchiyama M, Okawa M, Kim K, Shibui K, et al. Psychometric assessment of subjective sleep quality using the Japanese version of the Pittsburgh Sleep Quality Index (PSQIJ) in psychiatric disordered and control subjects. Psychiatry Res. 2000;97:165-72.

21. Buysse DJ, Reynolds CF 3rd, Monk TH, Berman SR, Kupfer DJ. The Pittsburgh Sleep Quality Index: a new instrument for psychiatric practice and research. Psychiatry Res. 1989;28:193-213.

22. e-Stat. Population estimates. https://www.e-stat.go.jp/en/stat-searc $\mathrm{h} /$ files?page $=1 \&$ layout $=$ datalist $\&$ lid $=000001054002$ (2019). Accessed 6 Apr 2019.

23. Liu XC, Uchiyama M, Kim K, Okawa M, Shibui K, Kudo Y, et al. Sleep loss and daytime sleepiness in the general adult population of Japan. Psychiatr Res. 2000;93:1-11.

24. Kaneita Y, Ohida T, Uchiyama M, Takemura S, Kawahara K, Yokoyama E, et al. The relationship between depression and sleep disturbances: a Japanese nationwide general population survey. J Clin Psychiatry. 2006;67:196-203.

25. Natale V, Plazzi G, Martoni M. Actigraphy in the assessment of insomnia: a quantitative approach. Sleep. 2009;32:767-71.

26. van den Berg JF, Luijendijk HJ, Tulen JH, Hofman A, Neven AK, Tiemeier H. Sleep in depression and anxiety disorders: a population-based study of elderly persons. J Clin Psychiatry. 2009;70:1105-13.

27. Ohayon MM, Carskadon MA, Guilleminault C, Vitiello MV. Meta-analysis of quantitative sleep parameters from childhood to old age in healthy individuals: developing normative sleep values across the human lifespan. Sleep. 2004;27:1255-73.

28. Ohayon MM. Epidemiology of insomnia: what we know and what we still need to learn. Sleep Med Rev. 2002;6:97-111.

29. Frankel BL, Coursey RD, Buchbinder R, Snyder F. Recorded and reported sleep in chronic primary insomnia. Arch Gen Psychiatry. 1976;33:615-23.

30. Hoch CC, Reynolds CF, Kupfer DJ, Berman SR, Houck PR, Stack JA. Empirical note-self-report versus recorded sleep in healthy seniors. Psychophysiology. 1987;24:293-9.

Publisher's Note Springer Nature remains neutral with regard to jurisdictional claims in published maps and institutional affiliations. 